\title{
Influência da Vazão e Geometria da Região de Entrada Sobre a Eficiência Térmica Medida por um Calorímetro de Fluxo Contínuo de Água
}

\author{
William Hackenhaar ${ }^{1}$, José Antônio Esmerio Mazzaferro ${ }^{1}$, Arnaldo Ruben Gonzalez ${ }^{1}$, Ivan Guerra Machado ${ }^{1}$ \\ 1 Universidade Federal do Rio Grande do Sul - UFRGS, Laboratório de Soldagem \& Técnicas Conexas, Porto Alegre, RS, Brasil.
}

Recebido: 13 Jan., 2016

Aceito: 10 Maio, 2016

E-mails: williamhackenhaar@gmail.com (WH), mazza@ufrgs.br (JAEM), ruben@mecanica.ufrgs.br (ARG), welder@ufrgs.br(IGM)
Resumo: O principal objetivo do presente trabalho é analisar a influência da vazão de água e da geometria na entrada de um calorímetro de fluxo contínuo sobre a eficiência térmica do arco. O procedimento experimental consiste em testar diferentes vazões de água e três configurações geométricas na região de entrada de água no calorímetro: com rolha reta, com difusor cônico e com obstáculo. Os experimentos foram planejados e os resultados avaliados com base na análise de variância estatística de um único fator, no caso, a vazão de água na entrada do calorímetro. Os cordões de solda foram depositados através do processo Gas Metal Arc Welding - GMAW, sobre tubos de aço baixo carbono, usando os mesmos parâmetros e tempo de soldagem. A maior eficiência térmica média de $80,5 \%$ foi obtida para a vazão de $4 \mathrm{l} / \mathrm{min}$, com baixo erro estatístico, utilizando rolha de entrada com geometria de difusor cônico, sendo que para vazões menores ou maiores ocorreu diminuição nos valores da eficiência medida. O modelo em que o fluxo entra diretamente no tubo apresentou todos os valores de eficiência térmica do arco com pequeno decréscimo numérico se comparados com o difusor cônico, enquanto a rolha com obstáculo apresentou elevado erro estatístico.

Palavras-chave: Vazão de água; Calorímetro; Eficiência térmica do arco; GMAW.

\section{Influence of Flow Rate and Inlet Geometry on the Thermal Efficiency of a Water Flow Calorimeter}

\begin{abstract}
The main aim of the present work is to analyze the influence of water flow rate and inlet geometry on the arc thermal efficiency of a continuous water flow calorimeter. The experimental procedure consists of varying water flow rate and testing three different calorimeter inlet seal geometries: straight seal, conical diffuser seal and seal with water flux obstacle. The experiments were designed and the results evaluated based in a one-factor statistical analysis of variance, in this case the inlet calorimeter water flow. The welding beads were deposited on low carbon steel pipes by Gas Metal Arc Welding - GMAW process, using the same parameters and welding time. The highest average thermal efficiency is $80.5 \%$ to water flow of $4 \mathrm{l} / \mathrm{min}$, with a low statistical error, using the conical diffuser seal inlet geometry, whereas for smaller or higher flow rates the measured efficiency values were lower. The inlet with straight seal model shown all the arc thermal efficiency values with slightly lower numerical values compared with conical diffuser, while the seal with flux obstacle exhibited high statistical error.
\end{abstract}

Key-words: Water flow; Calorimeter; Arc thermal efficiency; GMAW.

\section{Introdução}

Um dos primeiros problemas que surgem quando se analisa características e propriedades de uma junta soldada é a correta definição da energia utilizada. A parcela do calor que realmente é transferida para a peça é menor que o calor nominal imposto ou gerado pela fonte, pois ocorre a dissipação de parcela da energia. A determinação da verdadeira parcela do calor transferido para a peça leva em consideração algumas perdas inerentes a cada processo de soldagem, como por exemplo, perdas por respingos, condução, convecção, radiação, aquecimento do bocal da tocha, para o ambiente, através do metal de base adjacente antes da sua difusão para a poça de fusão e também o processo de soldagem que determina o fenômeno físico de transferência de calor e metal de adição, quando não autógeno, da tocha para a peça.

O principal objetivo do presente trabalho é avaliar a influência de diferentes vazões de água em um calorímetro de fluxo contínuo, assim como a alteração do escoamento através da variação da geometria de entrada do fluxo de água no sistema, sobre a eficiência térmica 
medida para o processo de soldagem GMAW. Assim, pretende-se melhor entender o fenômeno de transferência de calor do arco para a peça, adotando valores mais próximos aos da realidade para a eficiência do arco.

O calor imposto pelo arco representa a quantidade de energia entregue para a peça durante a soldagem, sua taxa é dada por unidade de comprimento do cordão em $(\mathrm{J} / \mathrm{mm})$. Os ciclos térmicos do substrato são dependentes dessa transferência de calor que determina a taxa de resfriamento da junta e, portanto, as transformações de fases, propriedades mecânicas, distorções, etc. A energia de soldagem é definida como a razão entre a potência da fonte de energia em Watts $(\mathrm{J} / \mathrm{s})$, e a velocidade de soldagem $(\mathrm{mm} / \mathrm{s})$, Equação 1 :

$$
E=\frac{U \cdot I}{v}\left(\frac{J}{m m}\right)
$$

Onde $E$ é a energia total ou nominal, $U$ é a tensão do arco elétrico em Volts, I é a corrente do arco em Amperes, e $v$ é a velocidade de soldagem.

Na avaliação da eficiência térmica para o processo GMAW controlado em calorímetros de nitrogênio líquido e caixa isolada realizado por Pépe et al. (2011), considerou-se que o calor não transferido para a peça é perdido nas formas de radiação, evaporação do metal de solda, convecção ou condução da tocha de soldagem, entre outros. Diferentes modelos para as perdas são encontrados na literatura com suas respectivas considerações e simplificações para permitir a melhor compreensão ou modelagem dos fenômenos. Segundo Scotti et al. (2012), entre os fatores que influenciam o calor imposto efetivo na peça, estão a condutividade térmica, comprimento do arco, gás de proteção, energia de soldagem (parâmetros), formato da poça fundida e ressalta-se a espessura devido a sua importância na quantidade de calor que é difundida pela chapa. Nesse contexto, é inserido o coeficiente adimensional que representa a eficiência térmica do arco $\eta_{a}$ para cada processo de soldagem, cuja correta determinação é fundamental para o correto uso dos modelos de transferência de calor em soldagem, pois afeta diretamente a potência ( $\eta \cdot U \cdot I)$. O cálculo da energia líquida $\left(E_{1}\right)$ com a consideração desse fator é dado pela Equação 2.

$$
E_{l}=\eta_{a} \frac{U \cdot I}{v}\left(\frac{J}{m m}\right)
$$

A eficiência do arco elétrico representa o calor que foi realmente transferido para a peça dividido pelo calor total gerado pela fonte de soldagem no período de tempo com arco aberto, a Equação 3 foi adaptada do trabalho de Dupont e Marder (1995) para o cálculo da eficiência do arco elétrico.

$$
\eta_{a}=\frac{Q_{a}}{P_{\text {inst }} \cdot t_{s}}
$$

Onde, o calor aportado pelo arco elétrico " $Q_{a}$ " pode ser medido por calorimetria, representando a taxa real de transferência de calor da fonte para a peça (descontando as perdas), " $t_{s}$ " é o tempo de soldagem ou tempo de arco estabelecido e, a potência média " $P_{\text {inst }}$ " é a média dos valores instantâneos medidos durante a soldagem segundo o trabalho de Nascimento et al. (2007), conforme Equação 4, e " $n$ " é o número de amostras da aquisição.

$$
P_{\text {inst }}=\frac{\sum_{i=1}^{n}\left(U_{i} \cdot I_{i}\right)}{n}
$$

Nos processos que utilizam eletrodo consumível, o metal de adição deve ser fundido pela fonte de calor à medida que é incorporado à junta, e conforme Kou (2003) o calor recebido pelo arame/eletrodo pode ser novamente transferido para a peça através das gotas de metal. Conforme citado por Dupont e Marder (1995), a transferência de calor em um eletrodo consumível, que possibilita sua fusão, provém principalmente do aquecimento resistivo do eletrodo e da absorção de elétrons na ponta do eletrodo originados pelo arco elétrico. No modelo descritivo proposto por Scotti et al. (2012) o fluxo de calor no processo GMAW ocorre de três maneiras principais: Primeiro, na conexão arco-peça em que o calor é transferido por condução para a peça gerando a poça de fusão, estima-se que mais de $80 \%$ de toda tensão do arco seja consumida na conexão entre arco-peça e arco-eletrodo. Segundo, através do calor carregado pelas gotas em transferência do eletrodo para a poça de fusão (metal de adição), onde uma porcentagem do calor é perdida para o ambiente como consequência da evaporação do metal e respingos. 
Influência da Vazão e Geometria da Região de Entrada Sobre a Eficiência Térmica Medida por um Calorímetro de Fluxo Contínuo de Água

Terceiro, através da energia da coluna de plasma que é transferida para a chapa (radiação e convecção). Entre as perdas, uma parte da energia imposta na superfície e que não é difundida para dentro da peça se perde para o ambiente por convecção através da superfície do cordão que acabou de solidificar.

A estimativa da eficiência de soldagem teórica e experimental vem sendo realizada de diversas maneiras, dentre elas pode-se destacar: o calorímetro de nitrogênio líquido estudado por Arevalo e Vilarinho (2012) que mede a perda de massa por vaporização, o calorímetro de efeito Seebeck investigado por Giedt et al. (1989), também o calorímetro que mede o aumento da temperatura da água de um recipiente após a imersão do corpo de prova conforme Bosworth (1991), e, ainda, o calorímetro de fluxo contínuo de água estudado por Lu e Kou (1989).

O calorímetro de fluxo contínuo utilizado no presente trabalho segue o princípio daquele proposto por Lu e Kou (1989), porém, com modificações geométricas. A concepção do funcionamento deste tipo de calorímetro é que através do escoamento contínuo de água com vazão controlada e constante no interior de um tubo extrai-se o calor da peça que recebe do arco elétrico, gerando o aumento da temperatura da água. Essa diferença de temperatura é medida na saída do tubo por termopares durante o período de tempo suficiente para o aquecimento da água pela passagem do arco elétrico e seu posterior resfriamento até retornar à temperatura ambiente. A quantidade de calor aportado à peça $\left(Q_{a}\right)$, é calculada pela Equação 5.

$$
Q_{a}=V \cdot \rho \cdot C p \cdot \sum_{i=0,1}^{n}(T s-T e) \cdot \Delta t
$$

Onde $V$ é a vazão de água $\left(\mathrm{m}^{3} / \mathrm{s}\right), C_{p}$ o calor específico da água em $\left(\mathrm{J} / \mathrm{kg} \cdot{ }^{\circ} \mathrm{C}\right), T_{s}$ a temperatura de saída $\left({ }^{\circ} \mathrm{C}\right)$, $T_{e}$ temperatura de entrada $\left({ }^{\circ} \mathrm{C}\right)$, $\rho$ é a massa específica $\left(\mathrm{kg} / \mathrm{m}^{3}\right)$ e $\Delta$ t é o período de tempo em de aquisição relativo à frequência configurada no sistema de aquisição de dados em segundos.

Entre os cuidados com esse tipo de calorímetro está a adequada escolha da vazão da água, que deve ser relacionada com a potência de soldagem. Baixas velocidades de escoamento poderiam produzir a ebulição da água. Por outro lado, como citado por Nasiri et al. (2014), o uso de altas taxas de vazão relativas à potência de soldagem poderia incrementar a retirada de calor da superfície da peça, diminuindo a temperatura da superfície de soldagem e também reduzindo o tamanho da poça de fusão. Nessa situação, podem resultar valores de eficiência artificialmente maiores, pois aumenta-se a transferência de calor para a peça devido ao arrefecimento acelerado da superfície.

\section{Materiais e Métodos}

O calorímetro utilizado neste trabalho foi desenvolvido no LS\&TC por Sgarbi (2013) e uma vista em corte da região de passagem da água pelo tubo é representada na Figura 1.

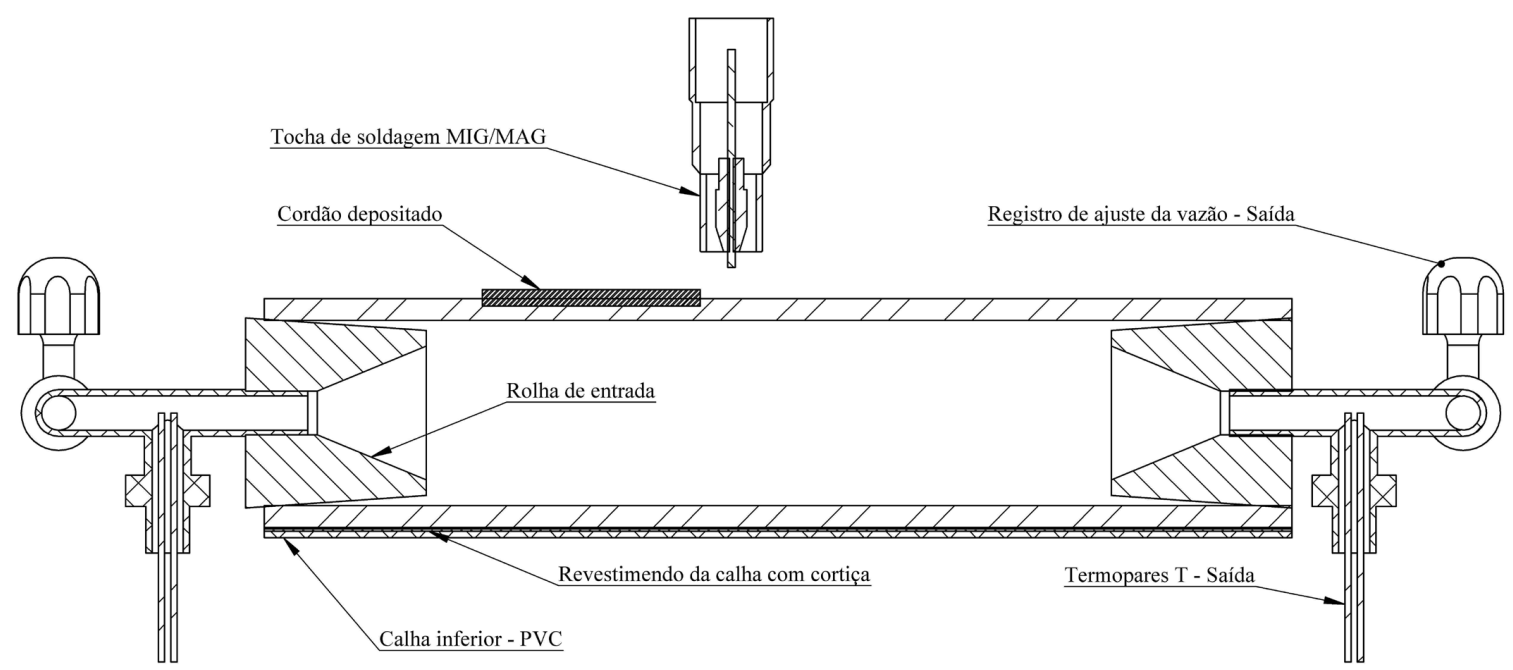

Figura 1. Vista de uma seção longitudinal do calorímetro. 
O tubo de aço que forma o corpo do calorímetro contém rolhas de borracha butílica na entrada e na saída, com superfície externa cônica e orifícios que permitem a passagem da água. Tal geometria facilita a montagem do sistema e permite boa vedação e possibilidade de variação do diâmetro interno do tubo. Os tubos são isolados por calhas revestidas por cortiça, de maneira a diminuir a troca de calor com o ambiente. A calha inferior permanece fixa durante o experimento, enquanto a superior é colocada logo após o término do cordão.

A aquisição da temperatura da água é realizada por termopares tipo T acoplados nas conexões de entrada e saída do corpo do calorímetro, posicionados no centro do duto de passagem da água. São utilizados dois termopares para a saída (medida do aquecimento e resfriamento da água) e dois termopares na entrada que medem a temperatura ambiente da água. A faixa de operação dos termopares tipo T é de $-200{ }^{\circ} \mathrm{C}$ a $350^{\circ} \mathrm{C}$ com sensibilidade de $50 \mu \mathrm{V} /{ }^{\circ} \mathrm{C}$ e limite de erro de $\pm 1{ }^{\circ} \mathrm{C}$. Os sinais de temperatura foram adquiridos com a frequência de $10 \mathrm{~Hz}$.

Para verificar a influência do fluxo de água na eficiência térmica medida pelo calorímetro, para uma energia constante, foram propostas três variações da geometria interna das rolhas de entrada: rolha com difusor cônico (rolha cônica), na qual o ângulo de abertura proposto foi de $45^{\circ}$ e não foram testados outros ângulos pois este atendeu de maneira satisfatória o objetivo proposto, cujas dimensões são mostradas na Figura 2a; rolha com face de entrada reta (rolha reta), conforme Figura $2 \mathrm{~b}$; e rolha com obstáculo ao fluxo de água, cuja geometria está detalhada na Figura 3. A rolha de saída para todos os ensaios foi a cônica, pois observou-se uma condição mais suave de afunilamento das linhas de fluxo com sua utilização, não ocorrendo choques ou turbulências na saída.
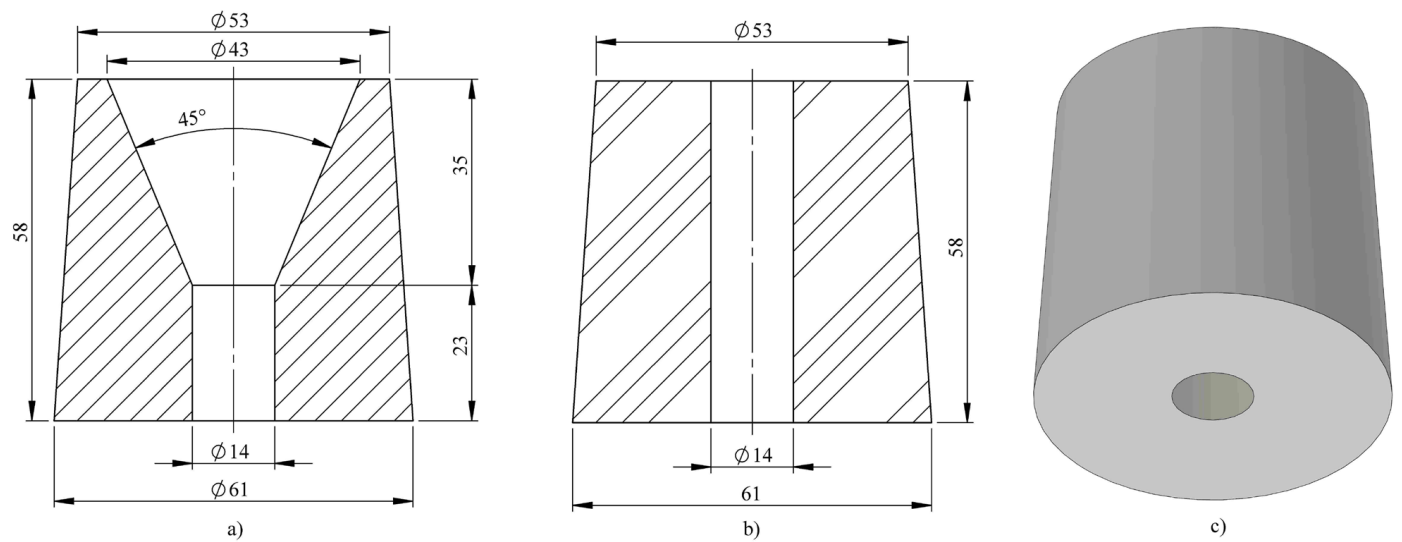

Figura 2. (a) Rolha com difusor cônico usinado internamente; (b) Rolha reta; (c) Vista isométrica.
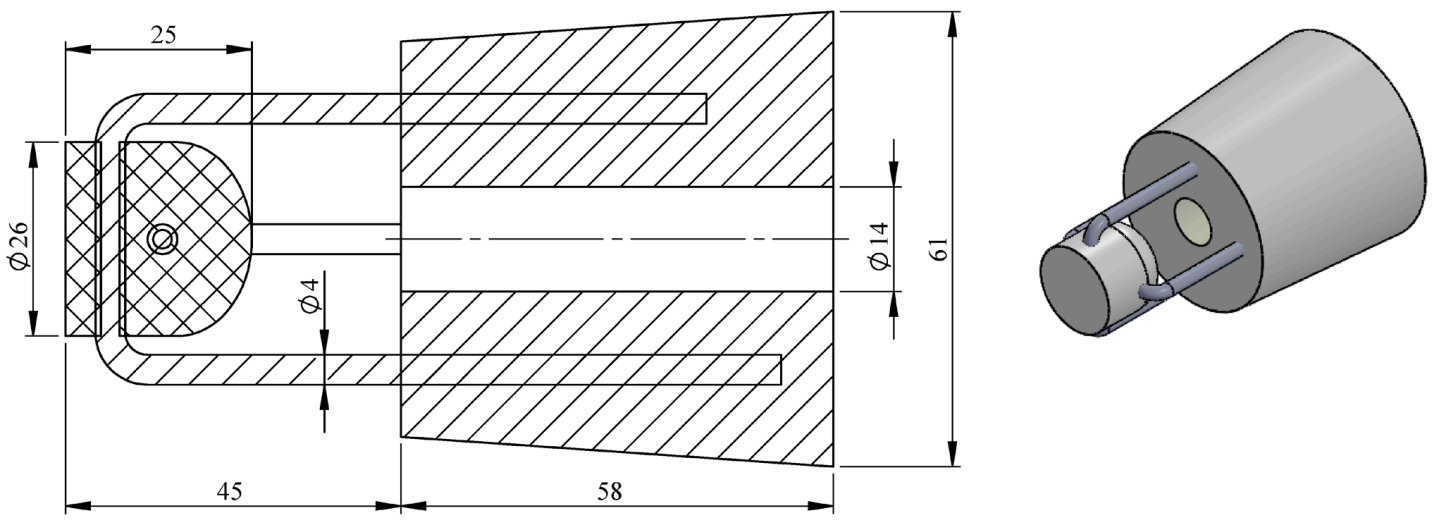

Figura 3. Rolha com obstáculo do fluxo de entrada com vista isométrica. 
Influência da Vazão e Geometria da Região de Entrada Sobre a Eficiência Térmica Medida por um Calorímetro de Fluxo Contínuo de Água

A avaliação criteriosa dos fenômenos envolvidos, no escopo da mecânica dos fluidos, para as três rolhas de entrada testadas, foge aos objetivos deste trabalho. Porém, de maneira superficial, observa-se que para um escoamento viscoso e incompressível em tubulação, os requisitos para avaliar fatores como perda de carga e o tipo de escoamento, laminar ou turbulento, não são satisfeitos, pois o comprimento de entrada é menor que o necessário para se estabelecer o escoamento completamente desenvolvido.

Segundo Çengel e Boles (2013), um difusor cônico, como o mostrado na Figura 2a, é um dispositivo que aumenta a pressão de um fluido pela sua desaceleração. A velocidade do fluido na saída do difusor é menor que em sua entrada, levando ao aumento da pressão para balancear a variação na energia cinética. Os difusores pertencem ao grupo das perdas de carga menores para o escoamento de fluidos, conforme Fox et al. (2014), um difusor possui escoamento tipicamente turbulento, e o aumento da pressão estática na direção do escoamento pode causar a separação do escoamento nas paredes, perdendo o contato entre o filme líquido e a superfície interna do tubo, se mal projetado.

A soldagem dos tubos foi realizada pelo processo GMAW convencional (fonte em modo tensão constante) com polaridade CC+. Para a execução dos experimentos utilizou-se um sistema robotizado, composto pela fonte TransPuls Synergic 4000 R da marca Fronius e pelo robô MA1400 da Yaskawa Motoman Robotics. A distância bico de contato peça (DBCP) foi de $15 \mathrm{~mm}$ com ângulo de deslocamento e trabalho neutros, o tempo de arco estabelecido foi de aproximadamente 40 segundos para todos os ensaios e os parâmetros de soldagem constantes, são apresentados na Tabela 1. O metal de adição foi o arame AWS ER70S-6 com 1,2 mm de diâmetro. Para o gás de proteção usou-se a mistura Argônio + 25\% de $\mathrm{CO}_{2}$ com vazão de $15 \mathrm{l} / \mathrm{min}$. Para os parâmetros utilizados, a transferência metálica ocorreu por curto-circuito, determinada em etapa preliminar aos ensaios descritos pela análise dos valores instantâneos de corrente e tensão coletados pelo Sistema de Aquisição Portátil SAP 4.01 (IMC Soldagem) para diversas combinações de tensão, corrente e velocidade de soldagem.

Tabela 1. Parâmetros de soldagem.

\begin{tabular}{ccc}
\hline $\mathbf{W}(\mathbf{m} / \mathrm{min})$ & $\mathbf{U}(\mathbf{V})$ & $\boldsymbol{v}(\mathbf{m m} / \mathbf{s})$ \\
4,5 & 20 & 4 \\
\hline
\end{tabular}

Os cordões de solda foram depositados sobre tubos de aço baixo carbono SCH 80 sem costura que atendem à norma NBR 5590 GRB com parede de 7,00 mm de espessura, 59,5 mm de diâmetro interno, 73,5 mm de diâmetro externo e $330 \mathrm{~mm}$ de comprimento para todas as amostras. A tensão de escoamento do material é de $332 \mathrm{MPa}$ e o limite de resistência de $487 \mathrm{MPa}$, segundo o laudo fornecido pelo fabricante. A Figura 4a apresenta uma vista geral do experimento, com caixa d' água, rotâmetro, calorímetro, tubo com calha e robô. Uma vista do calorímetro antes de depositar os cordões é apresentada na Figura 4b. O tubo com exemplo de cordões depositados é demonstrado na Figura 4c. Maiores detalhes sobre o calorímetro podem ser consultados em Sgarbi (2013) e Hackenhaar (2016).

A vazão de água foi medida na entrada do calorímetro através de um rotâmetro calibrado marca OMEL modelo 4T70903X12 para água, a incerteza de medição é de \pm 0,5\% e faixa de atuação de 0 a 3,0 l/min. Para os ensaios com vazões de 4,0 e 5,0 l/min mediu-se a vazão pela cronometragem do tempo e coleta da água em recipiente graduado. A água utilizada nos ensaios é oriunda de um reservatório com capacidade de 150 litros, evitando a entrada de bolhas de ar e também mantendo o fluxo de água e pressão constantes no sistema.

O planejamento experimental foi realizado utilizando-se a análise de variância de um fator único (ANOVA), possibilitando a determinação da confiabilidade do equipamento com embasamento estatístico, dessa maneira, realizou-se três ensaios (réplicas) para cada vazão (fator único). A sequência dos experimentos foi aleatorizada para evitar variáveis do ensaio que possam causar variações nos resultados (ruídos) que sejam desconhecidas. A vazão variou de 0,5 a 3,0 l/min com acréscimo de 0,5 l/min para os ensaios iniciais e, após verificar-se os resultados inconsistentes, a nova faixa de vazão foi definida entre 2,0 e 5,0 l/min com incremento de 1,0 l/min. O planejamento do experimento para cada tipo de geometria da rolha de entrada é exemplificado na Tabela 2 , com a indicação da faixa de vazões e respectivo número de réplicas sem aleatorização. 


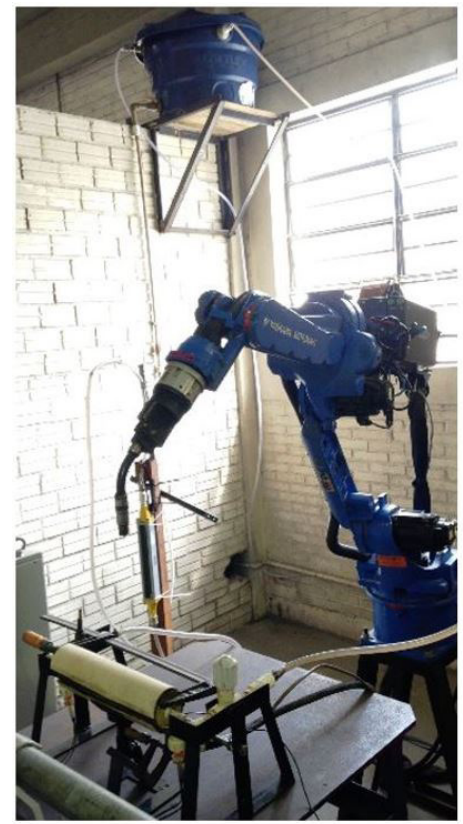

(a)

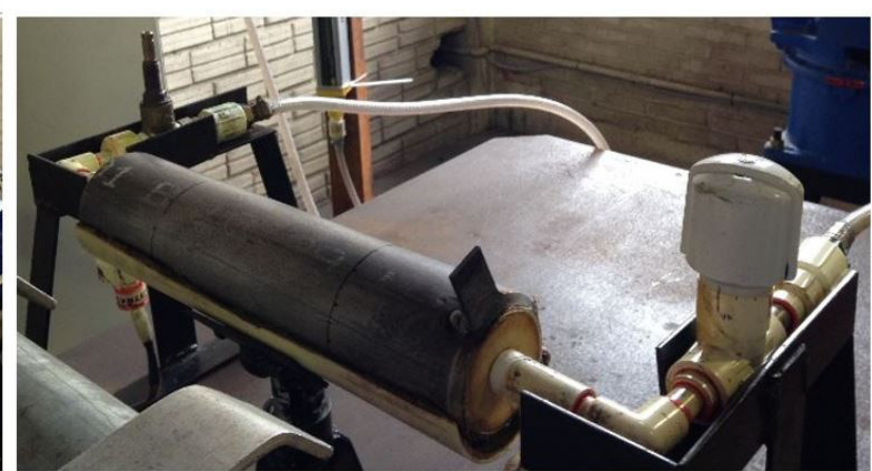

(b)

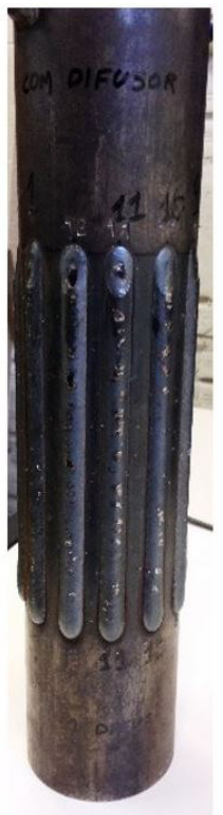

(c)

Figura 4. (a) Vista do experimento com o calorímetro; (b) Calorímetro antes da soldagem; (c) Exemplo dos cordões soldados nos tubos.

Tabela 2. Planejamento do ensaio com vazão (l/min) e número de réplicas sem aleatorização.

\begin{tabular}{ccccc}
\hline Réplicas & $\mathbf{2 , 0}(\mathbf{I} / \mathbf{m i n})$ & $\mathbf{3 , 0}(\mathbf{I} / \mathbf{m i n})$ & $\mathbf{4 , 0}(\mathbf{I} / \mathbf{m i n})$ & $\mathbf{5 , 0}(\mathbf{I} / \mathbf{m i n})$ \\
1 & 1 & 4 & 7 & 10 \\
2 & 2 & 5 & 8 & 11 \\
3 & 3 & 6 & 9 & 12 \\
\hline
\end{tabular}

A Tabela 3 exemplifica o experimento para a rolha cônica, com a ordem de realização dos ensaios e dados como Potência, Calor gerado e tempo de soldagem para o cálculo da eficiência térmica. Para todas as vazões o número de pontos considerado para o cálculo de $Q_{a}$ foi relativo ao tempo necessário para não haver diferença entre as temperaturas de entrada e saída, abrangendo todo o período de elevação e resfriamento da temperatura adquirida pelos termopares.

Tabela 3. Exemplo do ensaio com rolha cônica, representando a sequência de ensaio com respectivos valores aleatorizados, dados adquiridos e eficiência térmica resultante.

\begin{tabular}{ccccccc}
\hline $\begin{array}{c}\text { Sequência de } \\
\text { ensaio }\end{array}$ & $\begin{array}{c}\text { Sequência } \\
\text { aleatorizada }\end{array}$ & Vazão (I/min) & Potência $\mathbf{( W )}$ & $\begin{array}{c}\text { Calor gerado } \\
\mathbf{( k W )}\end{array}$ & $\begin{array}{c}\text { Tempo de } \\
\text { soldagem } \mathbf{( s )}\end{array}$ & $\begin{array}{c}\text { Eficiência } \\
\text { (n) }\end{array}$ \\
1 & 3 & 2 & 3957 & 112 & 40,0 & 69,8 \\
2 & 2 & 2 & 3963 & 110 & 40,0 & 69,6 \\
3 & 4 & 3 & 3929 & 116 & 40,0 & 73,7 \\
4 & 6 & 3 & 3912 & 115 & 39,9 & 73,4 \\
5 & 9 & 4 & 3874 & 126 & 39,8 & 81,9 \\
6 & 11 & 5 & 3892 & 103 & 40,0 & 66,4 \\
7 & 12 & 5 & 3902 & 109 & 40,1 & 69,5 \\
8 & 7 & 4 & 3887 & 122 & 40,0 & 78,5 \\
9 & 5 & 3 & 3910 & 114 & 40,1 & 72,8 \\
10 & 10 & 5 & 3912 & 106 & 40,1 & 67,4 \\
11 & 1 & 2 & 3951 & 113 & 41,0 & 69,9 \\
\hline
\end{tabular}


Influência da Vazão e Geometria da Região de Entrada Sobre a Eficiência Térmica Medida por um Calorímetro de Fluxo Contínuo de Água

\section{Resultados e Discussão}

Inicialmente, buscou-se avaliar se diferentes vazões de água no calorímetro resultariam em variação na variação de temperaturas medida pelos termopares e consequentemente na eficiência térmica. Como ponto de

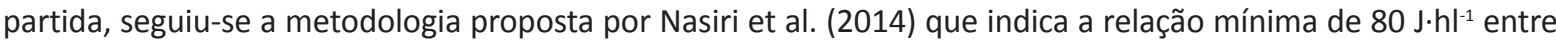
a potência do arco e a vazão de água. Observando essa proporção para os parâmetros de soldagem descritos anteriormente, obtém-se a vazão mínima recomendada de 0,6 l/min. Para verificar a adequação deste valor, foram feitos experimentos a partir da vazão de $0,5 \mathrm{l} / \mathrm{min}$ com incrementos da mesma ordem até atingir o valor de 3,0 $\mathrm{l} /$ min. Os valores de eficiência térmica resultantes são mostrados na Figura 5.

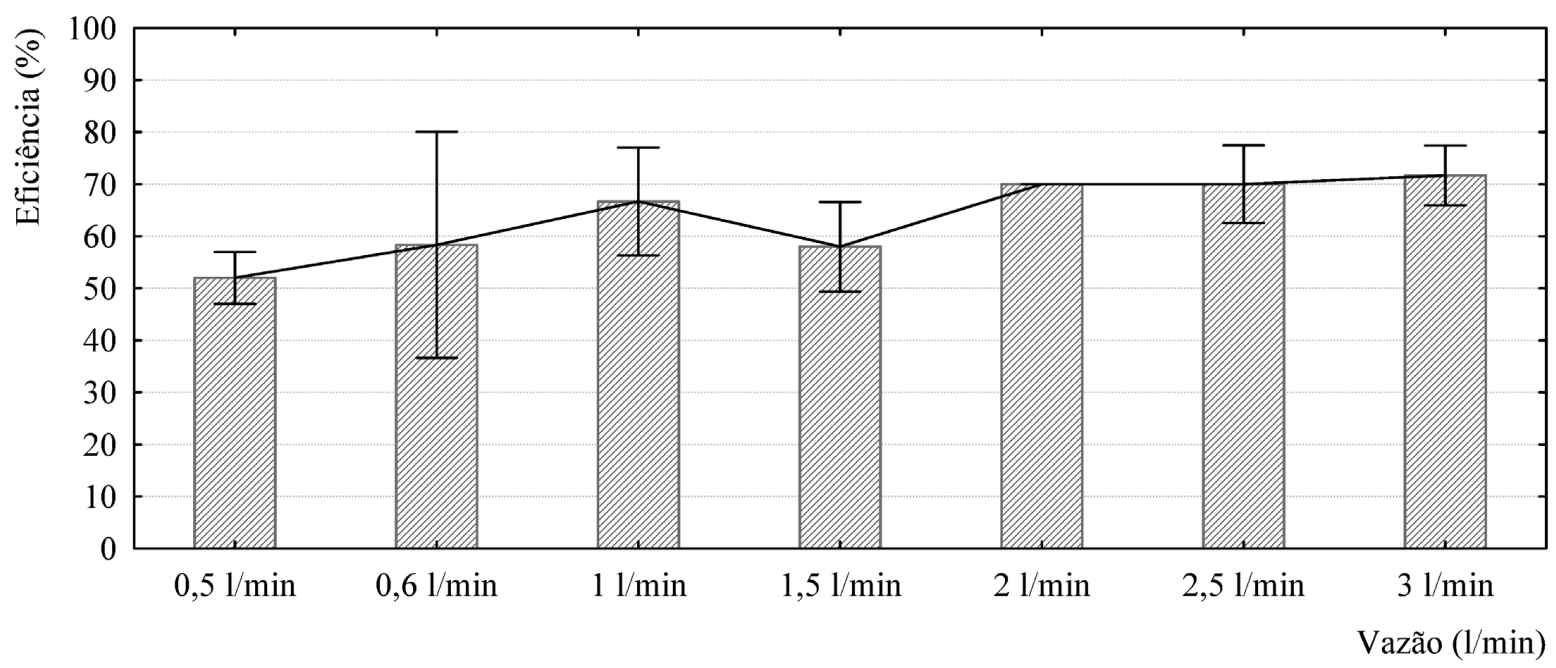

Figura 5. Ensaio inicial com baixas vazões, rolha cônica.

Os resultados mostram valores de eficiência térmica inferiores àqueles observados na literatura para o processo GMAW, particularmente para vazões inferiores a 2,0 l/min. Os ensaios foram aleatórios para a mesma potência, resultando valores de rendimento térmico sem repetitividade e com elevado erro estatístico. Uma possibilidade para a discrepância entre o valor da vazão sugerida por Nasiri et al. (2014) e o comportamento observado nos experimentos, está relacionada à geometria e/ou dimensões do calorímetro. Enquanto no presente trabalho os cordões foram depositados sobre tubos circulares, Nasiri et al. (2014) utilizaram um calorímetro tipo caixa, analisando a eficiência para o processo GTAW. Mesmo considerando os diferentes processos de soldagem como GMAW e GTAW, fisicamente a água aquecida pelo calor do arco elétrico que então é medida pelos termopares não distingue a fonte do calor, sugerindo a hipótese de que para cada geometria de calorímetro, tipo de conexões, estanqueidade e montagem existe determinada vazão de água que é mais adequada para medir o calor imposto pelo arco elétrico. Então, ampliou-se a faixa de vazões estudada de 2,0 a 5,0 l/min com incremento de 1,0 l/min e testou-se as demais rolhas.

Para visualizar o efeito da variação da vazão para cada um dos três tipos de rolhas de entrada, o tubo de aço foi substituído por um tubo de acrílico incolor de dimensões semelhantes, no qual foi injetado corante (azul de metileno) para facilitar a visualização das linhas de fluxo e possibilitar a análise do escoamento em cada situação.

As linhas de fluxo com os respectivos gráficos da aquisição de temperaturas são apresentadas nas Figuras 6-8, juntamente com os valores de calor aportado $(Q a)$, potência medida $(P)$ e eficiência térmica $(\eta)$ resultantes, para cada tipo de rolha utilizada. A aquisição de temperatura pelos termopares gerou os gráficos que estão ao lado das imagens do fluxo, nos quais, a área abaixo da curva determina o calor aportado pelo arco. Os gráficos mostrados nas Figuras 6-8 são aqueles mais próximos do valor médio observado pelas três repetições.

As imagens da Figura 6 mostram os escoamentos resultantes utilizando a rolha de entrada com obstáculo, com $20 \mathrm{~mm}$ de separação entre a saída de água e o início do domo. Este obstáculo foi utilizado para perturbar o fluxo de água no tubo e induzir vórtices, com a intenção de provocar turbulência generalizada, criando linhas de 

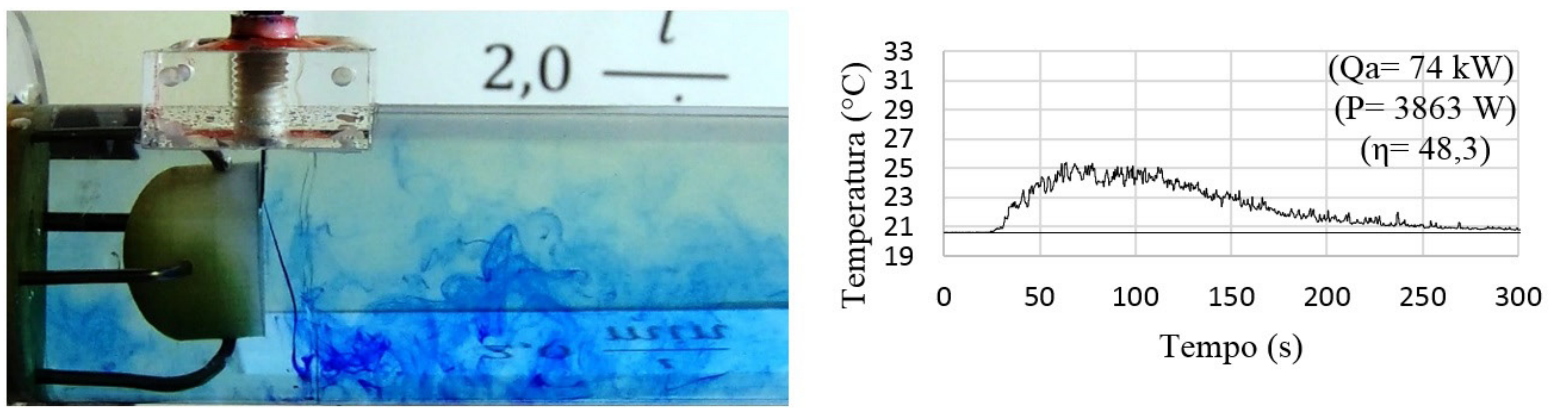

Figura 6.a (2,0 1/min).
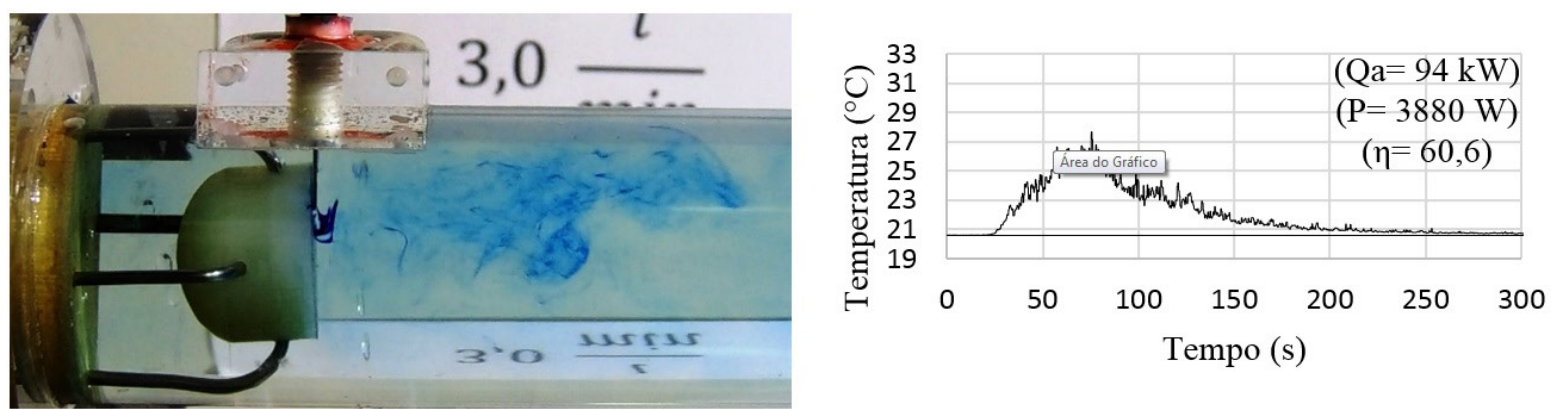

Figura $6 . b(3,01 / \mathrm{min})$.
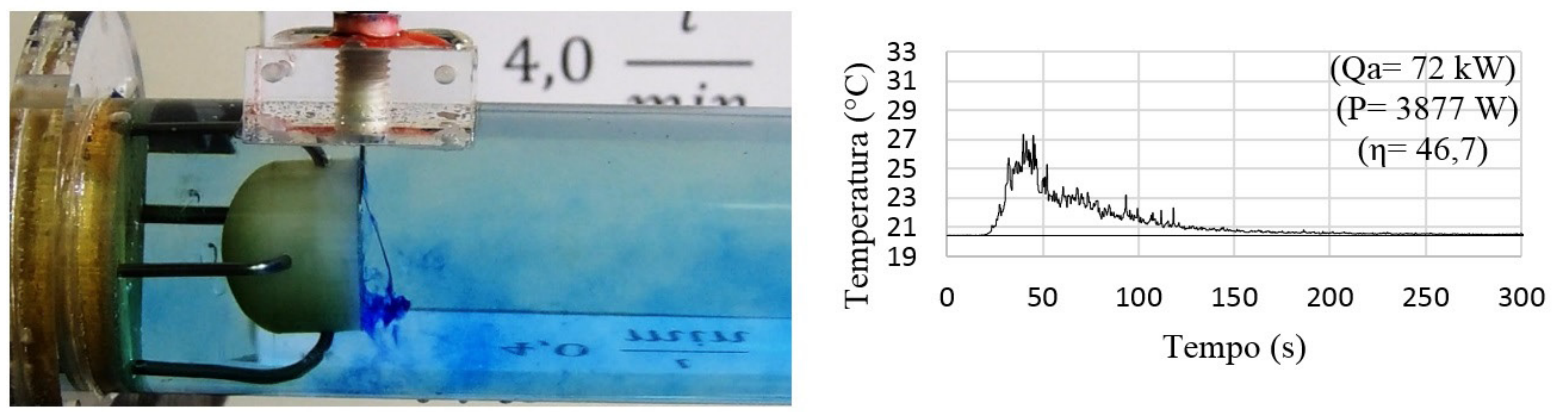

Figura 6.c (4,0 1/min).
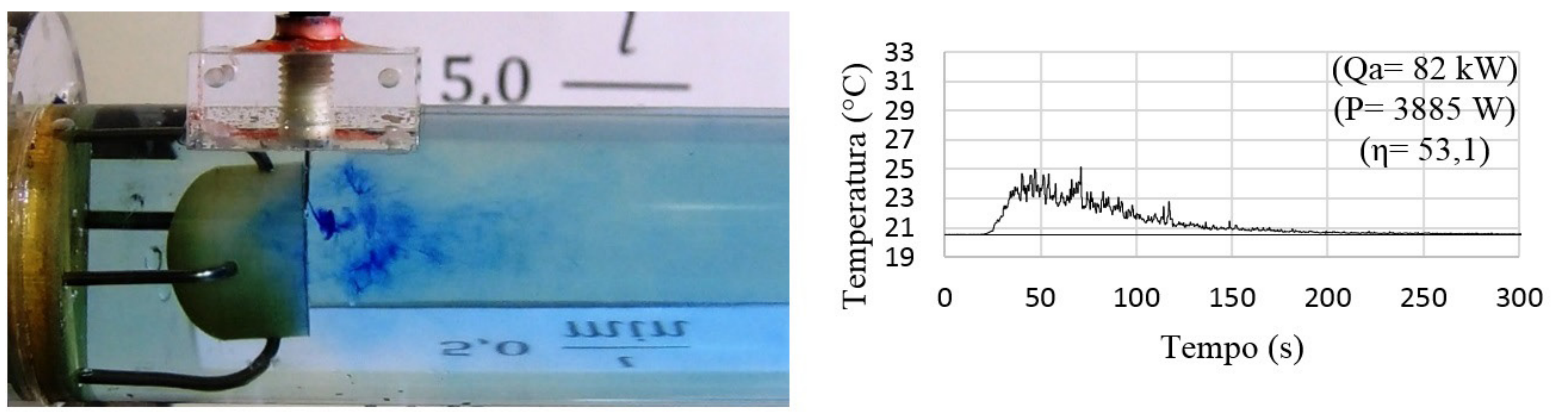

Figura $6 . \mathrm{d}(5,0 \mathrm{l} / \mathrm{min})$.

Figura 6. Linhas de fluxo do escoamento da água para a rolha com obstáculo e vazões de 2,0 a 5,0 l/min.

corrente com comportamento aleatório para a retirada do calor na parede e centro do tubo de forma homogênea. A análise dos valores para cada vazão evidencia os baixos valores e a grande variação das eficiências térmicas resultantes. Observando as linhas de fluxo é possível notar que, para todas as vazões estudadas, a introdução do obstáculo não foi efetiva para gerar turbulência que produzisse escoamento e extração de calor uniformes ao longo do tubo. 
Influência da Vazão e Geometria da Região de Entrada Sobre a Eficiência Térmica Medida por um Calorímetro de Fluxo Contínuo de Água

A Figura 7 apresenta o resultado dos experimentos realizados com a rolha reta. Neste caso, pode-se observar valores de eficiência térmica compatíveis com o processo de soldagem GMAW. A análise do escoamento mostra que o fluxo se distribui uniformemente ao longo do tubo, logo após o ponto de injeção do corante.
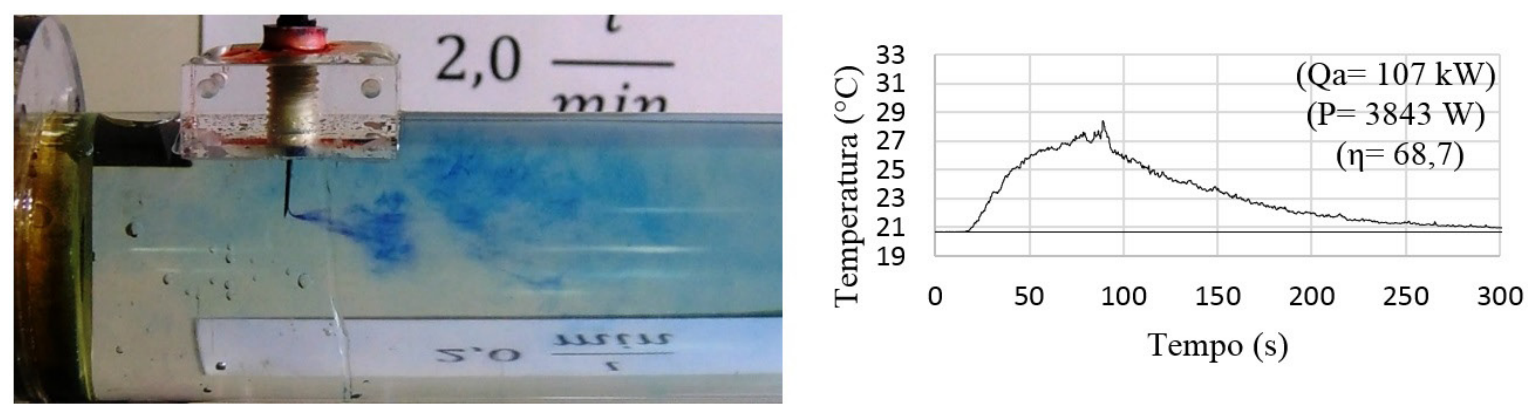

Figura 7.a (2,0 1/min).
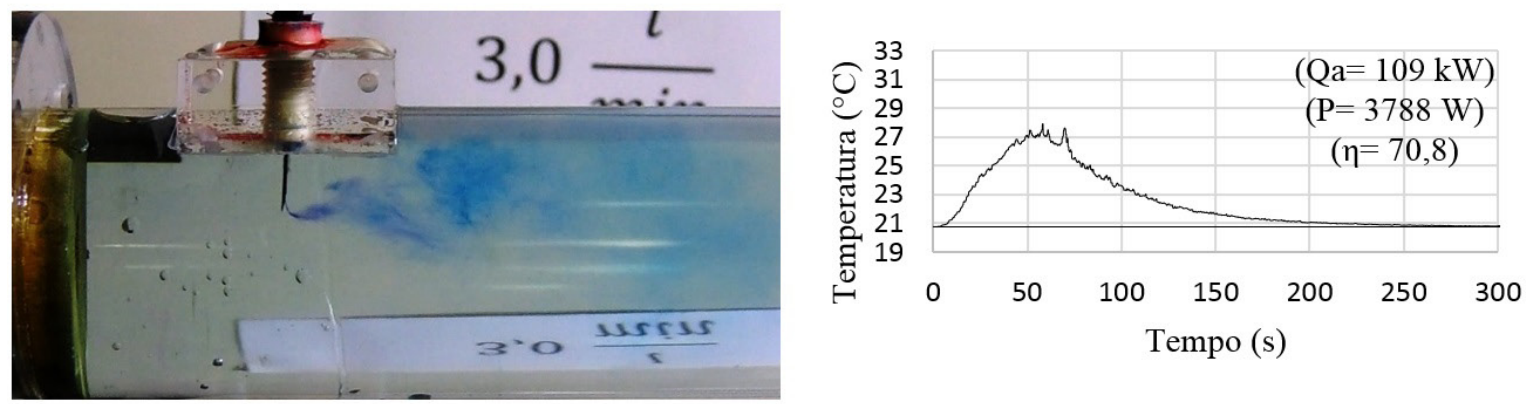

Figura $7 . b(3,01 / \mathrm{min})$.
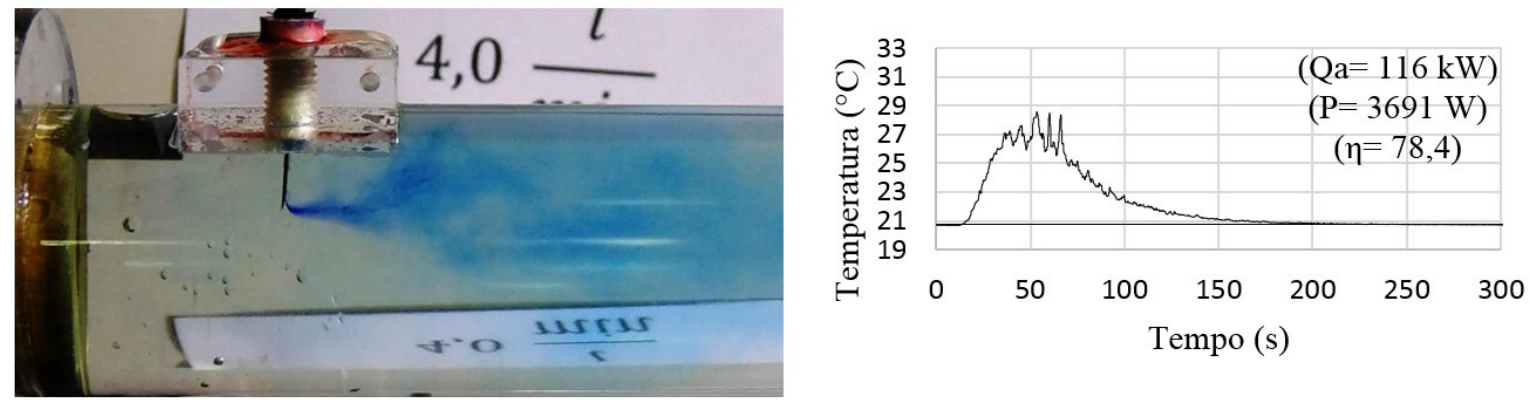

Figura $7 . c(4,0 \mathrm{l} / \mathrm{min})$.
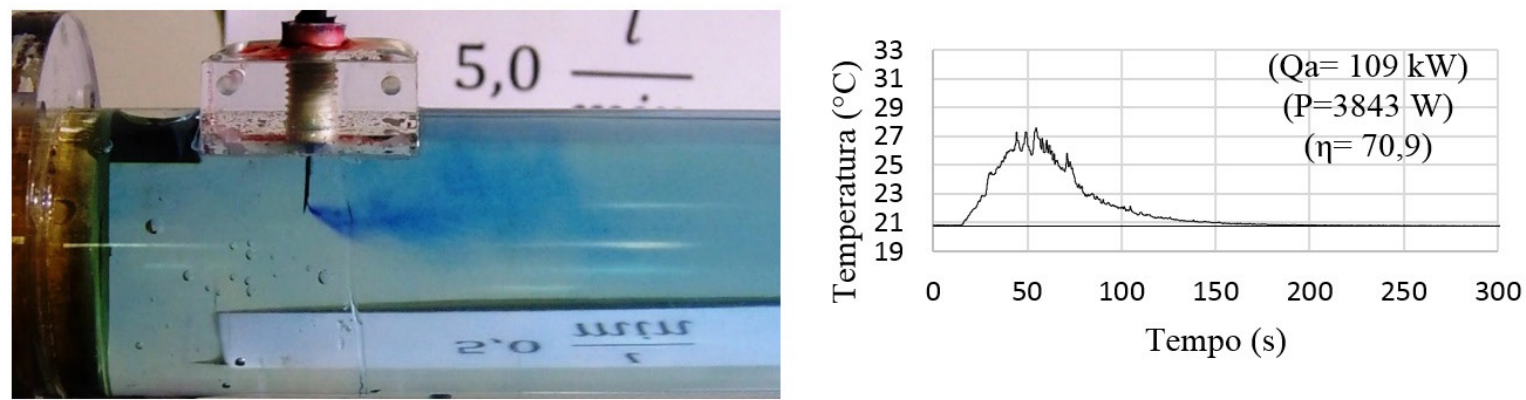

Figura $7 . d(5,01 / \mathrm{min})$.

Figura 7. Linhas de fluxo do escoamento da água para a rolha reta e vazões de 2,0 a 5,0 I/min.

A Figura 8 apresenta os resultados dos ensaios em que foi utilizada a rolha cônica. Os valores de eficiência térmica seguem a mesma tendência de aumento até a vazão de $4,0 \mathrm{l} / \mathrm{min}$, caindo para a vazão de $5,0 \mathrm{l} / \mathrm{min}$. Nesta situação os resultados numéricos são os mais próximos das eficiências térmicas para o processo GMAW 

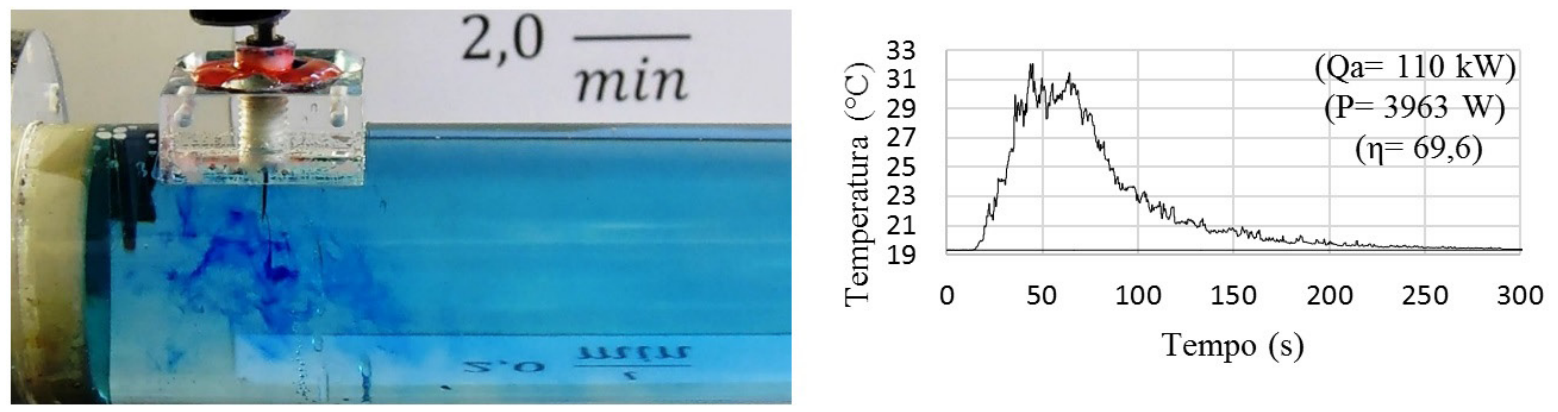

Figura 8.a (2,0 1/min).
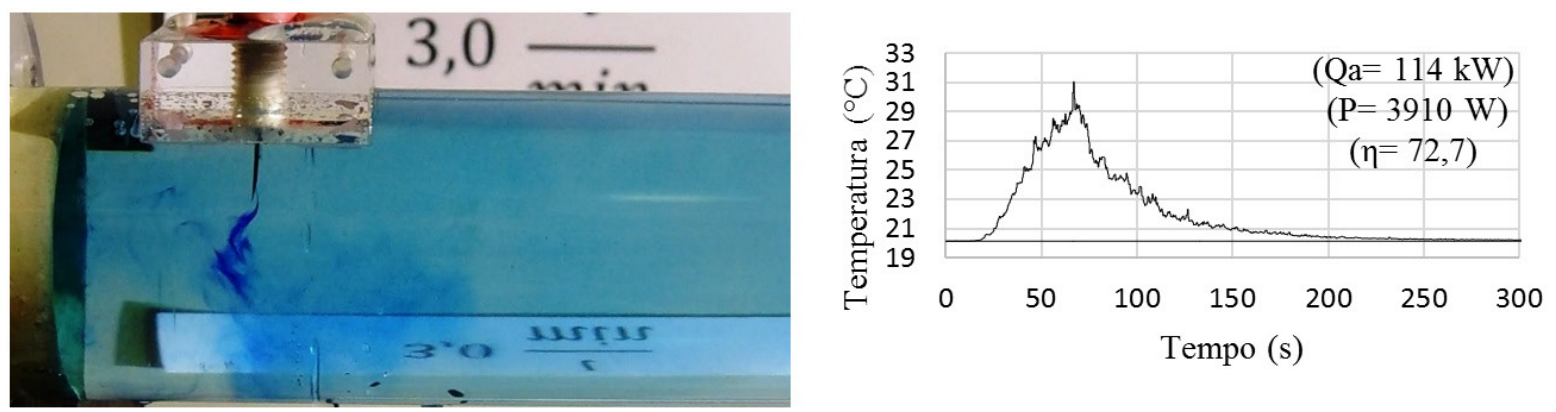

Figura $8 . b(3,01 / \mathrm{min})$.
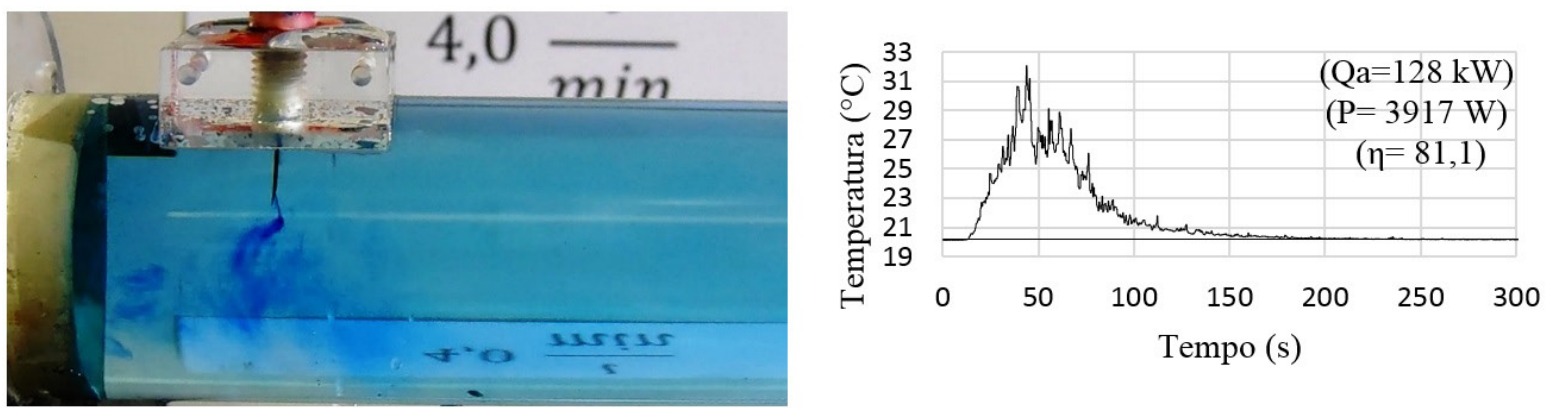

Figura $8 . c(4,01 / \mathrm{min})$.
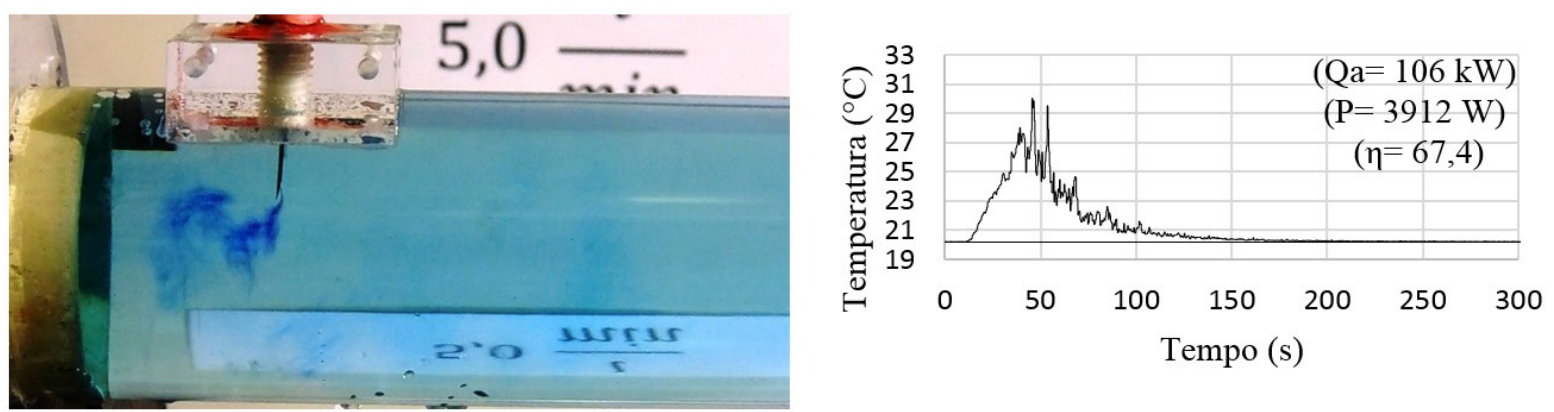

Figura 8.d (5,0 1/min).

Figura 8. Linhas de fluxo do escoamento da água para rolha cônica e vazões de 2,0 a 5,0 I/min.

indicados na literatura, com baixo erro estatístico. Com a vazão de 4,0 I/min se obteve o valor médio de $80,5 \%$ para a eficiência, sem diferenças sensíveis na geometria do cordão de solda, como penetração ou área fundida.

Além das consequências da perda de carga devido ao difusor cônico, o aumento da pressão e diminuição da velocidade, contribuem para o escoamento absorver o calor da parede do tubo de forma homogênea, efetiva e com menor dispersão dos resultados, quando comparada com as geometrias das outras rolhas. Tal constatação 
Influência da Vazão e Geometria da Região de Entrada Sobre a Eficiência Térmica Medida por um Calorímetro de Fluxo Contínuo de Água

pode ser observada visualmente através das imagens do fluxo e dos gráficos de temperatura. Pode-se notar que a utilização da rolha cônica antecipa a região de escoamento uniforme para as vazões de até $4,0 \mathrm{l} / \mathrm{min}$, sendo que a partir desse valor o aumento da vazão cria uma região de vorticidade que inverte o fluxo na entrada do calorímetro, reduzindo sensivelmente a eficiência térmica medida.

Na Figura 9 é apresentado um gráfico comparativo dos resultados de eficiência térmica medida em todos os experimentos. Os valores de eficiência com o uso da rolha com difusor cônico na entrada do calorímetro apresentaram os resultados mais elevados com vazão de $4,0 \mathrm{l} / \mathrm{min}$ sendo a média de $80,5 \%$ e, principalmente com baixa dispersão e erro estatístico.

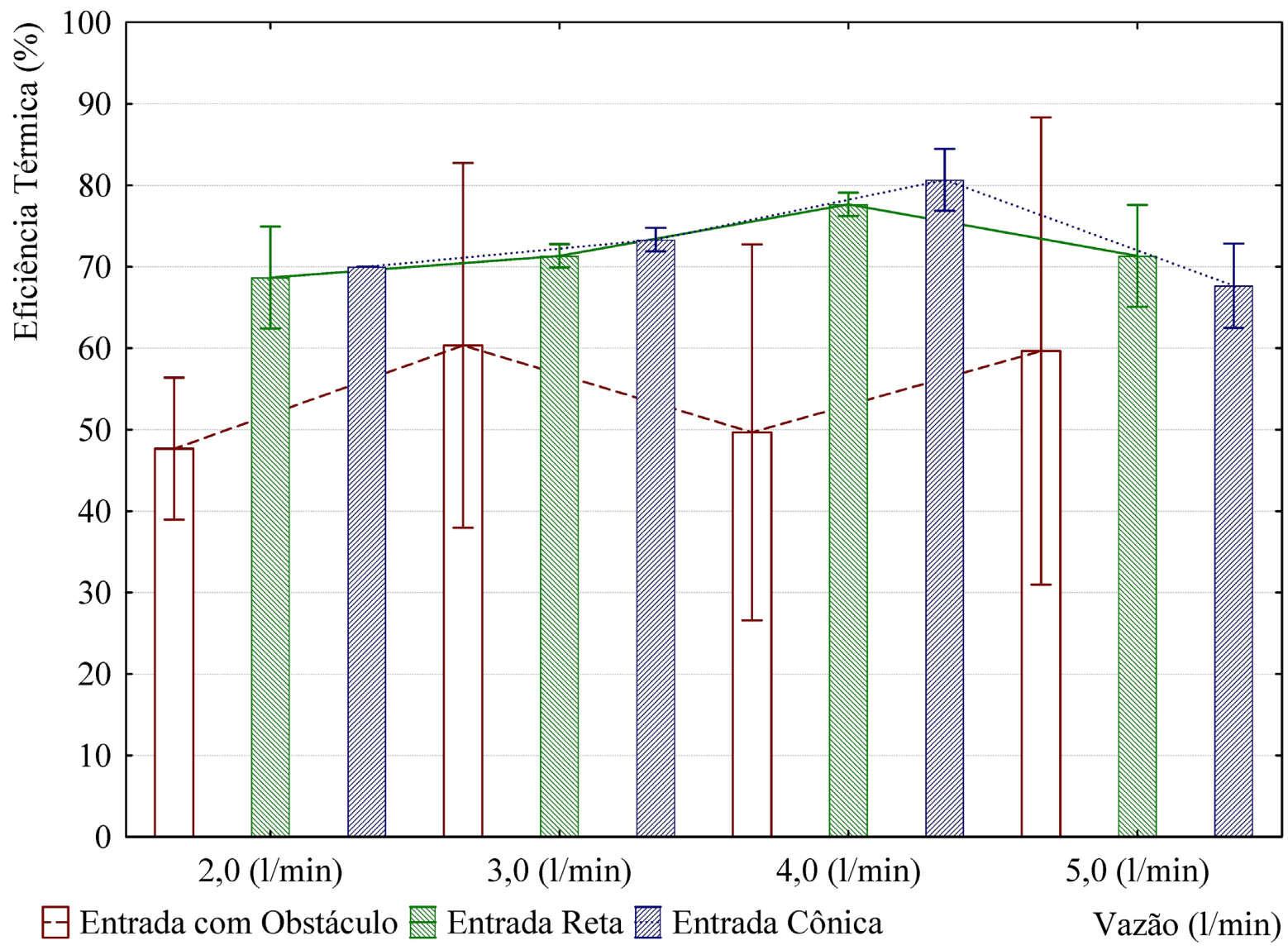

Figura 9. Eficiência térmica versus Vazão, para as diferentes vazões e rolhas de entrada.

Os resultados obtidos para a rolha reta também indicam repetitividade dos experimentos, com baixo erro estatístico. Os valores de eficiência térmica medidos foram ligeiramente inferiores àqueles apresentados pela rolha cônica, ainda assim, seguiram o mesmo padrão de comportamento para a relação entre eficiência térmica e vazão.

O uso da rolha com obstáculo produziu elevado erro de repetitividade, não permitindo estabelecer qualquer tendência de comportamento na relação vazão versus rendimento térmico. Na Tabela 4 são mostrados os valores dos parâmetros estatísticos para os três tipos de experimentos: teste F ANOVA (média quadrática dos tratamentos dividida pela média quadrática dos erros), e nível de significância, $p$-valor. A comparação entre os valores calculados com os dados experimentais e aqueles tabelados, mostra que há diferença significativa na eficiência térmica medida com a alteração da vazão de água quando as rolhas cônica e reta são utilizadas, o que não acontece quando a rolha com obstáculo é usada.

O valor de eficiência térmica encontrado por Dupont e Marder (1995) para o processo GMAW utilizando-se um calorímetro tipo Seebeck foi de $\eta_{\mathrm{a}}=0,84 \pm 0,04$. O material de base também foi aço de baixo carbono, porém, com espessura de $25 \mathrm{~mm}$ e diferente geometria, material de adição e tempo de arco aberto. 
Tabela 4. Comparação estatística eficiência versus vazão.

\begin{tabular}{lcccc}
\hline \multicolumn{1}{c}{ Tipo de rolha de entrada } & F calculado & F tabelado & p calculado & p tabelado \\
Com obstáculo & 1,67 & 4,07 & 0,2500 & 0,05 \\
Reta & 13,16 & 4,07 & 0,0018 & 0,05 \\
Cônica & 55,03 & 4,07 & 0,00001 & 0,05 \\
\hline
\end{tabular}

Os resultados foram próximos dos obtidos por Arevalo e Vilarinho (2012), em que foram encontrados valores de $78,6 \%$ para o processo GMAW curto circuito convencional com calorímetro de nitrogênio líquido, e valores de 70,5\% e $72,5 \%$ para o calorímetro de fluxo contínuo de água com vazão de $2,3 \mathrm{l} / \mathrm{min}$, os quais são próximos dos valores encontrados por este trabalho para 2,5 l/min, Figura 4, com média de 70,15\% para o uso da rolha cônica na entrada.

No trabalho de Bosworth (1991) para a investigação do calor imposto efetivo no processo GMAW, o autor encontrou valores de eficiência acima daqueles obtidos nesse trabalho quando comparados velocidade de alimentação de arame, tensão, gás e velocidade de soldagem, porém, utilizando material base com maior espessura. O valor de eficiência foi de $94 \%$ para a potência do arco de 2,1 kW que é a mais próxima da média medida de 1 kW deste trabalho. Para 5,4, 6,76 e 8,86 kW Bosworth (1991) encontrou 85, 86 e 83\% de eficiência, respectivamente. Como calorímetro, o autor utilizou um recipiente com água no qual a peça é imersa após a soldagem e então é monitorado o aumento da temperatura com termopares tipo K. A diferença entre os valores encontrados nos trabalhos pode estar na metodologia do cálculo para eficiência de Bosworth (1991), que usou a lei de Newton do resfriamento para calcular o calor recebido pela peça e, principalmente, na incerteza de $\pm 5 \%$ para a eficiência devido ao tempo de transferência da peça soldada para o calorímetro. Ainda, a potência do arco elétrico foi calculada como a média aritmética da tensão e corrente, diferente da média da potência instantânea deste trabalho, método aconselhado por Nascimento et al. (2007).

No estudo de Lu e Kou (1989) sobre a potência que incide na soldagem de alumínio pelo processo GMAW, os valores encontrados estão de acordo com os obtidos nesse trabalho. Os valores de eficiência térmica encontrados foram de $80 \%$ em geral para potências de até $7 \mathrm{~kW}$, ainda os autores atribuíram o valor global como sendo composto por três partes individuais, das quais, $45 \%$ para radiação/convecção, $23 \%$ para as gotas do metal de adição e $12 \%$ para o aquecimento do cátodo. Os valores individuais não foram verificados neste trabalho, no entanto, os fenômenos de transferência de calor estão de acordo com o previsto na literatura. É importante ressaltar que no trabalho de Lu e Kou (1989) utilizou-se alumínio como metal base com variação da espessura relativa à energia do arco elétrico, e em consequência ao modo de transferência metálica globular, mista e goticular ("spray").

Os valores de eficiência encontrados por Joseph et al. (2003), estiveram na faixa de 69 a $72 \%$ para o processo GMAW em tensão constante. O calor foi medido através de um calorímetro de nitrogênio líquido e, o metal base das amostras foi aço baixo carbono com 12,7 mm de espessura, 6,35 mm de largura e $152 \mathrm{~mm}$ de comprimento. Foi considerada a $\mathrm{P}_{\text {inst }}$ para a obtenção da potência média. Pode-se explicar a diferença nos valores de eficiência devido ao tempo necessário para inserir a peça soldada no recipiente com nitrogênio, após a soldagem (1,0-3,0 segundos), quando perde calor para o ambiente e, ainda devido a pequena largura do corpo de prova, que pode levar à contenção do calor aportado e aumentar as perdas por radiação e convecção quando comparadas ao processo natural de resfriamento.

\section{Conclusões}

O estudo para avaliar diferentes geometrias de entrada e vazões de água em um calorímetro de fluxo contínuo para o processo GMAW foi realizado, chegando-se às seguintes conclusões:

- Para o nível de energia de soldagem testado, a vazão de 4,0 l/min resultou no maior valor médio de eficiência térmica do arco, de 80,5\%, com decaimento no valor de eficiência para vazões inferiores ou superiores.

- O calor aportado influencia diretamente o valor da eficiência térmica do processo de soldagem medida por meio de um calorímetro de fluxo contínuo, sendo sensível ao tipo de entrada e de vazão da água. 
Influência da Vazão e Geometria da Região de Entrada Sobre a Eficiência Térmica Medida por um Calorímetro de Fluxo Contínuo de Água

- A análise estatística para as rolhas de entrada cônica e reta demonstrou baixo erro de repetitividade do experimento para todas as vazões, ao passo que para a rolha com obstáculo o erro estatístico foi elevado no intervalo de confiança considerado.

\section{Agradecimentos}

Um dos autores, William Hackenhaar, agradece à Coordenação de Pessoal de Nível Superior (CAPES) pela bolsa de mestrado que Ihe foi concedida.

\section{Referências}

Arevalo HDH, Vilarinho LO. Desenvolvimento e avaliação de calorímetros por Nitrogênio líquido e fluxo contínuo para medição de aporte térmico. Soldagem e Inspeção. 2012;17(3):236s-250s.

Bosworth MR. Effective heat input in pulsed current gas metal arc welding with solid wire electrodes. Welding Journal, USA. 1991;70(5):111s-117s

Çengel Y, Boles MA. Termodinâmica. 7. ed. Porto Alegre: AMGH Editora; 2013.

Dupont JN, Marder AR. Thermal efficiency of arc welding processes. Welding Journal. 1995;74(12):406s-416s.

Fox RW, Pritchard PJ, Mcdonald AT. Introdução à mecânica dos fluidos. 8. ed. Rio de Janeiro: LTC; 2014.

Giedt WH, Tallerico LN, Fuerschbach W. Welding efficiency: calorimetric and temperature field measurements. Welding Journal. $1989 ; 68(1): 28 s-32 s$

Hackenhaar W. Avaliação da eficiência térmica e de fusão na soldagem MAG em diferentes geometrias de juntas [dissertação de mestrado]. Porto Alegre: Universidade Federal do Rio Grande do Sul; 2016.

Joseph A, Harwig D, Farson DF, Richardson R. Measurement and calculation of arc power and heat transfer efficiency in pulsed gas metal arc welding. Science and Technology of Welding and Joining. 2003;8(6):400s-406s. http://dx.doi. org/10.1179/136217103225005642.
Kou S. Welding metallurgy. Hoboken: Wiley Interscience; 2003. 461 p.

Lu MJ, Kou S. Power inputs in gas metal arc welding of aluminum: part 2. Welding Journal. 1989;60(11):452s-456s.

Nascimento AS, Batista MA, Nascimento VC, Scotti A. Avaliação dos métodos de cálculo de potência elétrica em soldagem a arco e as consequências sobre as previsões geométricas, térmicas e metalúrgicas da junta. Soldagem e Inspeção. 2007;12(2):97s-106s

Nasiri MB, Behzadinejad M, Latifi H, Martikainen J. Investigation on the influence of various welding parameters on the arc thermal efficiency of the GTAW process by calorimetric method. Journal of Mechanical Science and Technology. 2014;28(8):3255s-3261s

Pépe N, Egerland S, Colegrove PA, Yapp D, Leonhartsberger A, Scotti A. Measuring the process efficiency of controlled gas metal arc welding processes. Science and Technology of Welding and Joining. 2011;16(5):412s-417s

Scotti A, Reis RP, Liskevych O. Modelo descritivo do fluxo de calor em soldagem a arco visando o conceito de calor imposto efetivo. Soldagem e Inspeção. 2012;17(2):166s-172s.

Sgarbi P. Construção e validação de um calorímetro com vazão contínua de água para avaliação do rendimento térmico em processos de soldagem [dissertação mestrado]. Porto Alegre: Universidade Federal do Rio Grande do Sul; 2013. 